\title{
Selection of Indigenous Algal Species for Potential Biodiesel Production
}

\author{
Vinaya Tiwari ${ }^{1 *}$ (D) ${\text { Alok } \text { Das }^{2} \mathbb{D} \text {, Shallu Thakur }}^{2}$ (D) and Rakesh Kumar Trivedi ${ }^{1}$ \\ ${ }^{1}$ Department of Oil Technology, Harcourt Butler Technical University, Kanpur - 208002 India. \\ ${ }^{2}$ Division of Plant Biotechnology, ICAR-Indian Institute of Pulses Research, Kanpur - 208024 India.
}

\begin{abstract}
Currently, India utilizes an enormous amount of fossil fuels and a major quantity of fossil fuels are imported from other countries. It's a giant load on the Indian Economy. The burning of fossil fuels causes global warming. Carbon neutral, renewable fuels are essential for environmental protection and it's economically sustainable for India. Biofuels attention day by day due to a rise in energy demands and environmental concerns. Biodiesel produced from algal oil a possible renewable and carbonneutral substitute to fossil fuels. The feasibility of the algal-based biodiesel industry depends on the selection of adequate species regarding commercial oil yields and oil quality. Present research work to bioprospecting and screening of 19 algal and blue-green algal species, the oil percentage and the fatty acid profiles, used for analyzing the biodiesel fuel properties. Oil from Tolypothrix phyllophila algal strain and compared it with another eighteen algal and blue-green algal strains from different literature. Tolypothrix phyllophila algal strain contains approximately $12.6 \%$ lipid on a dry weight basis. We also compared the FAME profile of 19 algal and blue-green algal strains and calculated and compared the fuel properties such as cetane number, lodine Value, etc. of the biodiesel derived from these algal and blue-green algal oils based on chain length and saturation. We also investigated the 19 algal and blue-green algal fatty acid profiles and its suitability for biodiesel production and strains selection through PROMETHEE (Preference Ranking Organization Method for Enrichment Evaluations) and GAIA (geometrical analysis for interactive aid) analysis.
\end{abstract}

Keywords: Biodiesel, FAME, Cetane number, PROMETHEE \& GAIA

*Correspondence: vinayatiwari@rediffmail.com

(Received: September 10, 2020; accepted: April 22 2021)

Citation: Tiwari V, Das A, Thakur S, Trivedi RK. Selection of Indigenous Algal Species for Potential Biodiesel Production. J Pure Appl Microbiol. 2021;15(2):851-863. doi: 10.22207/JPAM.15.2.40

(C) The Author(s) 2021. Open Access. This article is distributed under the terms of the Creative Commons Attribution 4.0 International License which permits unrestricted use, sharing, distribution, and reproduction in any medium, provided you give appropriate credit to the original author(s) and the source, provide a link to the Creative Commons license, and indicate if changes were made. 


\section{INTRODUCTION}

Prolong utilization of fossil fuels is set to face various challenges: continued and significant fuel price rise, including global warming, and other environmental issues, depletion of fossil fuels reserves ${ }^{1,2}$.

Besides the limited amount of fossil fuels, global dependence of fossil energy brings about associated problem emissions. Fossil fuels are the dominating source of carbon dioxide and other greenhouse gases $(\mathrm{GHGs})^{2,3}$.

These problems specify an unsustainable condition. Renewable energy is the only key to growing energy challenges. Sources of renewable energy such as wind, tidal energy, wave, solar, and biomass energy are rich, environment friendly and inexhaustible ${ }^{4,5}$.

Biofuel is said as liquid or gaseous fuel, synthesized from biomass ${ }^{6}$. A variety of biofuels are synthesized from biomass resources including liquid fuel like ethanol, methanol, biodiesel, and, gaseous fuels such as hydrogen and methane, 8 . Because of several reasons, biofuels are considered relevant for energy needs in developing countries and developed countries. It includes savings, energy security basis, foreign exchange, environmental concern, and socio-economic concerns associated with the agriculture area ${ }^{7,9,10}$.

In all forms of biofuels, algal biofuels are the most effective source of energy compared to other ${ }^{11}$, because biofuel crops compete with the conventional crops for land and other resources for its growth therefore the threat to food security, while algae are often grown in polluted land as well as contaminated water bodies s,12,13,14. $^{9}$.

Production and utilization of biodiesel have been growing since the 1980s and with increasing commercialization of biodiesel, demand for standardization has taken centre-satge. US, India, Europe now have adapted biodiesel guidelines ${ }^{15}$. Few of the biodiesel properties regulated by these guidelines cannot be directly calculated by most analysts because the specialized equipment are often missing and, particularly in algal biodiesel pilot studies, the quantity of oil produced is too little. However, there have been various attempts to devise models that estimate some of the critical biodiesel properties from its content.

These models permit the initial estimation of potential feedstocks (algae and blue-green algae) if the fatty acid composition is well-known. Suitability of any material as fuel, including biodiesel, is depend on the skeleton of the fatty acids as well as ester derived from the base alcohol ${ }^{16}$. The properties of a biodiesel are determined by the structure of its fatty esters component included (Saponification Value) SV, (Cetane Number) CN, (Cold Filter Plugging Point) CFPP, (lodine Value) IV, etc.

In the current study, we investigated the lipid content in Tolypothrix phyllophila and FAME examinations of lipid extracted by this strain by GC-MS. We also compared the FAME profile of 19 algal and blue-green algal species. On the basis of FAME profile of fatty acids of these 19 algal and blue-green algal species, we calculated the fuel properties such as Cetane Number, lodine Value, Saponification Value, Degree of Unsaturation, Long Chain Saturation Factor, and Cold Filter Plugging Point. Based on these fuel properties, we compared the biodiesel produced by these 19 algal and blue-green algal species by PROMETHEE and GAIA software.

The current research describes the importance of the fatty acid profile on these fuel properties. Not all of these fuel properties have been incorporated as specifications in biodiesel standards, although all of are necessary for the optimal performance of the fuel.

\section{MATERIALS AND METHODS Algal Culture}

Tolypothrix phyllophila (NAIMCC-C00047), a microalgae strain was collected from ICAR- National Bureau of Agriculturally Important Microorganisms (NBAIM), Mau, Uttar Pradesh, India. A slant culture was procured and subcultured in BG-11 media ${ }^{17}$ for further studies at the Harcourt Butler Technical University, Kanpur. We also took the 18 algal and blue-green algal species ( Table no. 1) from different literature for comparative analysis.

\section{Lipid content and FAME Analysis}

Total lipid content of Tolypothrix phyllophila was estimated using the Soxhlet method $^{18}$, as a percentage of the total biomass (in \% dry weight). The algal strain was grown aseptically. Algae pellet was dried at $80^{\circ} \mathrm{C}$ for $4 \mathrm{~h}$ in hot air oven (Navyug Udyog, Haryana, India). The 
Soxhlet extraction unit (Borosil, India) was filled with the solvent mixture containing Chloroform: Methanol $(2: 1)^{19}$ in the heating mantle (Perfit, India) of the unit, followed by heating the solvent mixture to extract the lipid out of the dried algal sample from a thimble, which is subsequently collected in the bottom flask. The solvent was then separated from the lipid content by the distillation process. The mixture was heated to the boiling point of the solvent that selectively evaporate the solvent, leaving behind the lipid content. The lipid content was measured based on the weight of lipid extract compare to the dry weight of algal biomass.

The isolated lipid was converted into biodiesel by transesterification reaction using ethanol and lipid (6:1 ratio) in the presence of base catalysis $(\mathrm{NaOH})^{20,21,22,23,24}$.

The resultant methyl esters was evaluated by Gas Chromatograph-Mass Spectrometry (GCMS, model 7890/5977B, Agilent Technologies, USA $)^{25}$ connected to autosampler, split-splitless injector, flame ionization detector (FID), and a $60 \mathrm{~m}$ BPX70 capillary column (SGE, Ringwood, Australia) having $0.25 \mathrm{~mm}$ internal diameter and $0.25 \mu \mathrm{m}$ film thickness. Samples of $1 \mu \mathrm{L}$ were injected at $60^{\circ} \mathrm{C}$, held for $3 \mathrm{~min}$, before raising by $40^{\circ} \mathrm{C} / \mathrm{min}$ to $150^{\circ} \mathrm{C}$ and then sequentially by $1.5^{\circ} \mathrm{C} / \mathrm{min}$ to $230^{\circ} \mathrm{C}$. The constant flow mode of helium carrier gas with an estimated average velocity of $30 \mathrm{~cm} / \mathrm{s}$ was used in the analysis. As per manufacturer instructions, injector and detector temperatures were set at $250^{\circ} \mathrm{C}$ and $300^{\circ} \mathrm{C}$, correspondingly. The fatty acid profile was recorded using Mass Hunter workstation software version B.04.07 by Agilent Technologies USA.

The analysis showed that in the above 19 algal and blue-green algal strains, Microcystis aeruginosa has the highest percentage of oil $(28.15 \%)$ in comparison to other algal and bluegreen algal strains, while Phormidium purpurescens species have $26.45 \%$ of oil. The Phormidium ambiguum has a minimum oil percentage (10.48\%) in comparison to other strains.

\section{Calculation of Biodiesel Properties Based on FAME Profiles}

Based on oil percentage we could not decide that this is the most excellent algal strain for biodiesel production, because the fuel properties of microalgal biodiesel were dependent on fatty acid profile ${ }^{29}$. Continuous research has been undertaken to improve the quality of algal biodiesel. Biodiesel production and its commercialization were done since the 1980 s. Commercialization requires the standardization of algal biodiesel. US, Europe, the Republic of South Africa, Brazil, Australia and India now have their biodiesel guidelines ${ }^{30,31,32}$.

Fatty acid methyl ester (FAME) of algal biodiesel may change according to carbon chain sizes and the position and/or number of double bonds ${ }^{16,33}$. The main properties of biodiesel such as lodine value (IV), Cetane Number, oxidation stability, and Cold Filter Plugging Point (CFPP) was directly influenced by these molecular structures ${ }^{16,34,35,36}$. Biodiesel properties such as Saponification Value (SV), Cetane Number (CN), Iodine Value (IV), Degree of Unsaturation (DU), Cold Filter Plugging Point (CFPP), and Long Chain Saturated Factor (LCSF) were determined by the empirical equations.

\section{Cetane Number}

The cetane number (CN) is the determination of the ignition properties of the fuel. It is connected to the ignition delay time ${ }^{30}$; $31,37,38$. Generally, the higher the $\mathrm{CN}$, the better the ignition quality of the diesel and vice versa. The $\mathrm{CN}$ of fuel depends upon the structure of the compound comprising the mixture. The $\mathrm{CN}$ increases with increasing saturation and increasing chain length. Aromatic and branched compounds have a low cetane number ${ }^{38,39}$.

For the No. 2D diesel ASTM standard was determined to be $53.2 \mathrm{~min}$ in the case of the cetane number ${ }^{40}$. According to Indian Standards (IS 15607:2005), the minimum cetane number for Biodiesel (B 100) is $51^{41}$.

The $C N$ of the FAME mixture was calculated by the empirical equation given by Krisnangkura ${ }^{42}$. The $\mathrm{CN}$ can be calculated with the following equation no. $1^{43,44}$.

$$
C N=46.3+\frac{5458}{S V}-(0.225 \times I V)
$$

\section{Saponification value}

Saponification Value (SV) means milligrams of potassium hydroxide required to saponify $1 \mathrm{~g}$ of oil, it is inversely connected to the esters molecular weight. It can be calculated by 
the following equation no. $2^{43,44}$.

$$
S V=\sum \frac{(560 \times N)}{M}
$$

\section{lodine Value}

lodine value (IV) essentially indicates the tendency of any fuel to react with oxygen at ambient temperature, which in turn depends on the position and number of double bonds in the carbon chains of the cognate alkyl esters. The higher the iodine value (the mass of iodine in grams that is consumed by $100 \mathrm{~g}$ of a chemical substance) the higher the possibility of deposit formation, oxidation, and deterioration of the biodiesel lubricity. The IV can be calculated by the following equation no, $3^{43,44}$.

$$
I V=\sum\left(\frac{254 \times D \times N}{M}\right)
$$

$D$ is the no. of double bonds, $\mathrm{N}$ is the \% of each fatty acid component and $\mathrm{M}$ is the Molecular mass.

The Degree of unsaturation was calculated by the following equations no. $4^{43 ; 44}$

$$
D U=M U F A+(2 \times P U F A)
$$

Where MUFA means the weight percentage of Monounsaturated fatty acids and PUFA means the weight percentage of Polyunsaturated fatty acids.

\section{Cold-flow characteristics}

More saturated and longer chain FAMEs have higher melting points in compare to shorter chains and more unsaturated FAMEs. Fuels with a huge concentration of SFAs can have poor coldflow properties and unsuitable viscosities. At low temperatures, saturated components of the fuel crystallize and precipitate causing troubles, such as clogged pumps, fuel lines, filters, and injectors ${ }^{16,31,33,45}$. To avoid problems with cold flow properties, it is essential for biodiesel have relatively high levels of unsaturated FAMEs and so relatively low concentrations of saturated FAMEs ${ }^{45}$.

The Long Chain Saturation Factor (LCSF) was measured by the following equations no. 5 .
This properties was correlated with CFPP and calculated by using equation no. $6^{44,46}$.

$$
L C S F=(0.1 \times C 16)+(0.5 \times C 18)+(1 \times C 20)+(1.5 \times C 22)+(2 \times C 24)
$$

$C F P P=(3.1417 \times L C S F)-16.477$

Where $\mathrm{C} 16, \mathrm{C} 18, \mathrm{C} 20, \mathrm{C} 22, \mathrm{C} 24$ are the weight percentage of each fatty acids (wt\%).

It should be well-known that the properties of Fatty Acids/Fatty Acid Mehtyl Esters that impart a favorable Cetane Number on a fuel (long-chain and low degree of unsaturation) impart minimum cold-flow properties and viscosities ${ }^{39,47}$. It is, so, essential to achieve a balance between Cetane Number and cold-flow properties. Fatty Acid Methyl Esters that attain this balance are the monounsaturated methyl hexadecenoate (C16:1) and methyl octadecenoate $(\text { C18:1 })^{48,49}$. Biofuels rich in these Fatty Acid Methyl Esters will have good enough Cetane Numbers, viscosities, and cold-flow parameters. The ideal biodiesel fuel feedstock would be composed totally of C18:1 and C16:1 Mono Unsaturated Fatty Acids ${ }^{48}$, thus in practice, a biodiesel feedstock should contain hudge concentrations of $\mathrm{C} 18: 1$ and $\mathrm{C} 16: 1$, that are as hudge as feasible and so maintain the concentrations of all other Fatty Acids as minimum as feasible. However, feedstocks will contain mixed Fatty Acid compositions and will have non-ideal Fatty Acids. It is, so, essential to quantify the maximum acceptable levels of other Fatty Acids (not Mono Unsaturated Fatty Acids) in biodiesel fuel and to make this model that predicts the fuel properties such as CN, CFPP, and viscosity from FA composition have to be used.

\section{Selection of Suitable Algal Species for Biodiesel}

The selection of best algal strains done by using PROMETHEE and GAIA analysis ${ }^{29,50}$. with the selected criteria Yield, CN, SV, IV, CFPP. Here we use Visual PROMETHEE Software 1.4.0.0 Edition for comparative analysis of algal and blue-green algal strains. We draw a graph by PROMETHEE-GAIA software with multiple criteria by giving equal weightage to all criteria. This graph a comparative analysis and gives the phi value to all 19 strains. Based on phi value the best strain for biodiesel production. 


\section{Statistical Analysis}

A variety of multi-criteria decision analyses (MCDA) are available. Here we utilized Preference Ranking Organisation Method for Enrichment Evaluation (PROMETHEE) and Graphical Analysis for Interactive Assistance (GAIA) for selection of best algal strains. These softwares are utilized in various research paper for suitability analysis of algal strain for biodiesel production.

\section{RESULTS}

\section{Lipid content and FAME Analysis}

Based on the Soxhlet method, Tolypothrix phyllophila culture was estimated to contain approximately $12.6 \%$ lipid on a dry weight basis. The lipid content obtained by the above method was converted into esters of fatty acids (biodiesel) by standard transesterification method, and the resultant product was analyzed by GC-MS. FAME analysis led to the identification of constituent of the trans-esterified product or biofuel, principally containing, Palmitic acid $\left(\mathrm{C}_{16: 0}\right)(31.6 \%)$ and oleic acids $\left(\mathrm{C}_{18: 1}\right)(23.3 \%)$ in excess amount (Table 2 ). We also observed that Tolypothrix phyllophila contains $46.7 \%$ total saturated fatty acids, $28.7 \%$ MUFA, and $20.5 \%$ PUFA.

\section{Calculation of Biodiesel Fuel Properties Based on Fatty Acid Methyl Esters Profiles}

Based on FAME profiles of algal and blue-green algal strains, we estimated the total saturated fatty acids, MUFA, and PUFA present in different algal and blue-green algal species as shown in Table 3.

On the basis of the equations no. 1 to 6 , we calculated the CN, SV, IV, DU, LCSF, and CFPP as shown in table 4.

\section{Selection of best Algal Strain for Biodiesel production}

To be a perfect source of sustainable biodiesel, the selected algal strain should have the sufficient proportion of lipids with suitable fatty acids. A multi-criteria decision method (MCDM) software PORMETHEE-GAIA was used to construct objective selections for hudge amount production.

The selection of suitable species was done based on above calculated biodiesel fuel properties (CN, IV, SV, DU, LCSF, and CFPP) with the help of PROMETHEE-GAIA software.

The following figure number 2 shows the GAIA plot of one algal strain from the current study and eighteen algal and blue-green algal strains from different literature as shown in table 1 ,

Table 1. Oil percentage in Tolypothrix phyllophila from this study and other eighteen algal and blue-green algal strains from literature

\begin{tabular}{|c|c|c|c|}
\hline S. No. & Species & Oil Percentage \% & References \\
\hline 1. & Tolypothrix phyllophila & 12.72 & - \\
\hline \multicolumn{4}{|c|}{ Nineteen strains from references } \\
\hline 2. & Chlorococcum sp. & 11 & {$[26]$} \\
\hline 3. & Chlorella sp. & 15 & [26] \\
\hline 4. & Scenedesmus sp. & 24 & [26] \\
\hline 5. & Spirulina sp. & 20 & [27] \\
\hline 6. & Chlorella sp. & 26 & {$[27]$} \\
\hline 7. & Oscillatoria calcuttenis & 25.7 & [28] \\
\hline 8. & Oscillatoria acuminate & 24.65 & [28] \\
\hline 9. & Nostoc linckia & 18.45 & {$[28]$} \\
\hline 10. & Calothrix fusca & 22.6 & [28] \\
\hline 11. & Lyngbya limnetica & 18.1 & [28] \\
\hline 12. & Phormidium purpurescens & 26.45 & [28] \\
\hline 13. & Microcystis aeruginosa & 28.15 & [28] \\
\hline 14. & Lyngbya dendrobia & 10.55 & [28] \\
\hline 15. & Oscillatoria perornata & 14.10 & [28] \\
\hline 16. & Phormidium ambiguum & 10.48 & [28] \\
\hline 17. & Oscillatoria amoena & 18.63 & {$[28]$} \\
\hline 18. & Scytonema bohnerii & 22.22 & [28] \\
\hline 19. & Oscillatoria chlorina & 16.62 & [28] \\
\hline
\end{tabular}




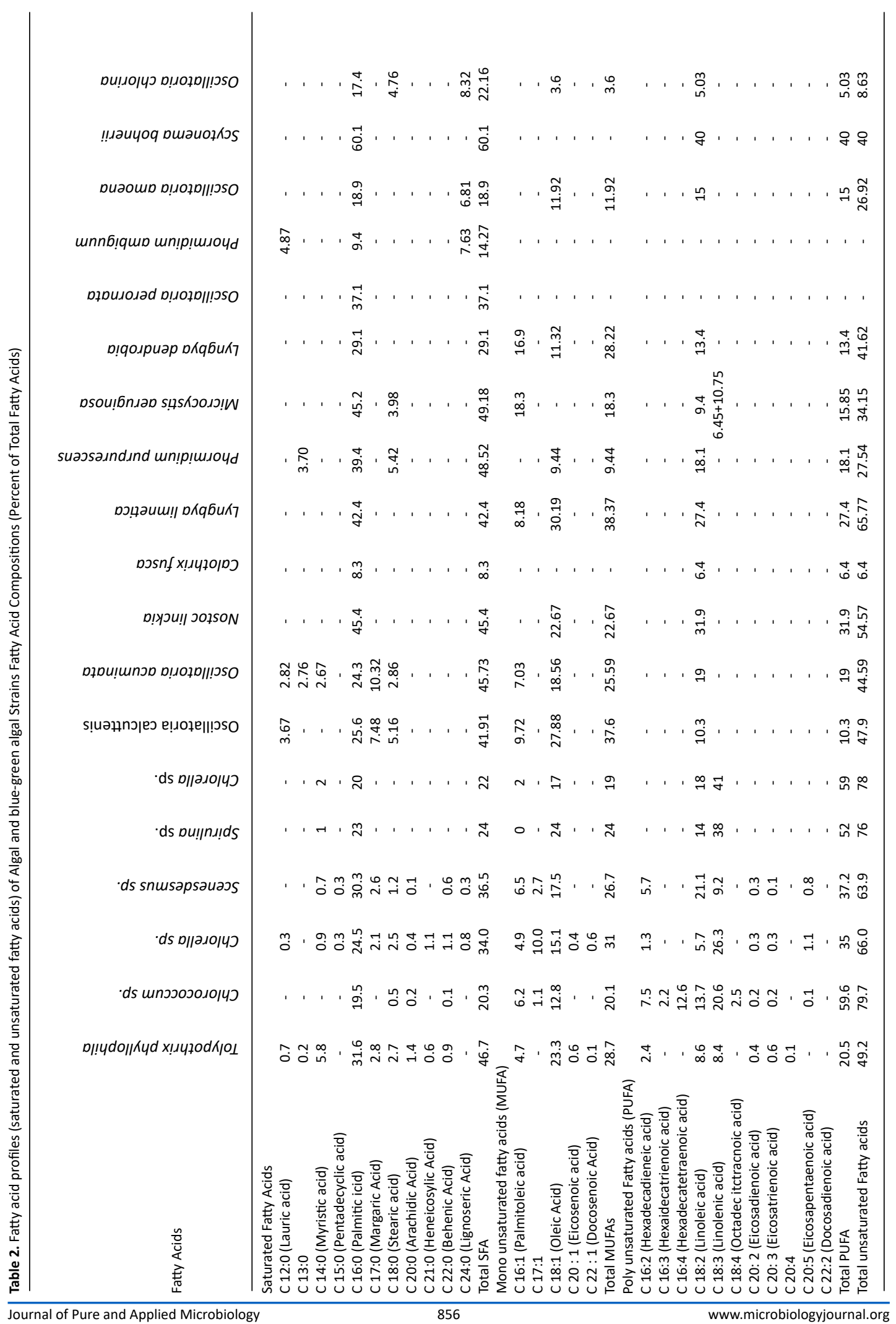


based on different biodiesel properties from table no. 4 and the decision vector. CN, SV, IV, DU, LCSF, CFPP, and total lipid contents, are given equal. The decision vector that is long and not orthogonal (at the right angle) to the GAIA plane is ideal for decision making ${ }^{51}$. The decision vector shows the most appropriate strain, i.e., those that align with the direction of this vector, and the outermost criteria in the direction of the decision vector are the most preferable ${ }^{52}$.

In contrast, $\mathrm{Db} \geq 4, \mathrm{SAFs}$, and $\mathrm{C} 18: 3$ were extremely variable criteria (Table 4) and they had a strong effect on the decision vector. According to Fig. 2 and the calculated outranking flows, the most appropriate strains are Chlorella $s p$. and Phormidium ambiguum with the highest phi value in all 19 species (Fig. 2, Table no. 5). Calothrix fusca and Lyngbya dendrobia remained their low ranking with low phi value and are the least appropriate strain for biodiesel production.

\section{DISCUSSION}

Biofuels are the current need of the world, given the depleting carbon resources and the footprint it generates. Microalgae are one of the potential sources of bio-fuels.

Oil content (\% in $\mathrm{dwt}$ ) and growth rate have been the two criteria for the success of large scale cultivation of algae for biofuel production ${ }^{53}$. The qualitative lipid composition and the lipid volumetric productivity should be considered as the most suitable parameters to facilitate decision making on strain selection for biodiesel production $^{54}$.

The present study, pertains to the analysis of lipid content in Tolypothrix phyllophila. The algal strain is native to the Baharaich region (Geographical coordinate $27.7525^{\circ} \mathrm{N}, 81.4279^{\circ} \mathrm{E}$ ) of Uttar Pradesh, India.

In this present study Tolypothrix phyllophila culture was estimated to contain approximately $12.6 \%$ lipid on a dry weight basis. The present study showed that among 19 algal and blue-green algal strains the lipid \% on dry weight varies between 10.48 to $26.45 \%$, in these strains more than $25 \%$ lipid on a dry weight basis found in Chlorella sp. $26 \%{ }^{27}$, Oscillatoria calcuttenis 25.7 $\%$, Phormidium purpurescens $26.45 \%$ lipid on a dry weight basis ${ }^{28}$.

Table 3. Total lipid percentage, percentage of saturated fatty acids, MUFA and PUFA in algal and blue-green algal strains

\begin{tabular}{|c|c|c|c|c|c|}
\hline $\begin{array}{l}\text { S. } \\
\text { No. }\end{array}$ & Species Name & $\begin{array}{c}\text { Total } \\
\text { lipid (\%) }\end{array}$ & $\begin{array}{l}\text { Saturated } \\
\text { fatty acids }\end{array}$ & $\begin{array}{l}\text { Monounsaturated } \\
\text { fatty acids } \\
\text { (MUFA) }\end{array}$ & $\begin{array}{c}\text { Polyunsaturated } \\
\text { fatty acids } \\
\text { (PUFA) }\end{array}$ \\
\hline 1. & Tolypothrix phyllophila & 12.72 & 46.7 & 28.7 & 20.5 \\
\hline 2. & Chlorococcum sp. & 11 & 20.3 & 20.1 & 59.6 \\
\hline 3. & Chlorella sp. & 15 & 34.0 & 31 & 35 \\
\hline 4. & Scenesdesmus sp. & 24 & 36.5 & 26.7 & 37.2 \\
\hline 5. & Spirulina sp. & 20 & 24 & 24 & 52 \\
\hline 6. & Chlorella sp. & 26 & 22 & 19 & 59 \\
\hline 7. & Oscillatoria calcuttenis & 25.7 & 41.91 & 37.6 & 10.3 \\
\hline 8. & Oscillatoria acuminate & 24.65 & 45.73 & 25.59 & 19 \\
\hline 9. & Nostoc linckia & 18.45 & 45.4 & 22.67 & 31.9 \\
\hline 10. & Calothrix fusca & 22.6 & 8.3 & - & 6.4 \\
\hline 11. & Lyngbya limnetica & 18.1 & 42.4 & 38.37 & 27.4 \\
\hline 12. & Phormidium purpurescens & 26.45 & 48.52 & 9.44 & 18.1 \\
\hline 13. & Microcystis aeruginosa & 28.15 & 49.18 & 18.3 & 15.85 \\
\hline 14. & Lyngbya dendrobia & 10.55 & 29.1 & 28.22 & 13.4 \\
\hline 15. & Oscillatoria perornata & 14.10 & 37.1 & - & - \\
\hline 16. & Phormidium ambiguum & 10.48 & 14.27 & - & - \\
\hline 17. & Oscillatoria amoena & 18.63 & 18.9 & 11.92 & 15 \\
\hline 18. & Scytonema bohnerii & 22.22 & 60.1 & - & 40 \\
\hline 19. & Oscillatoria chlorine & 16.62 & 22.16 & 3.6 & 5.03 \\
\hline
\end{tabular}




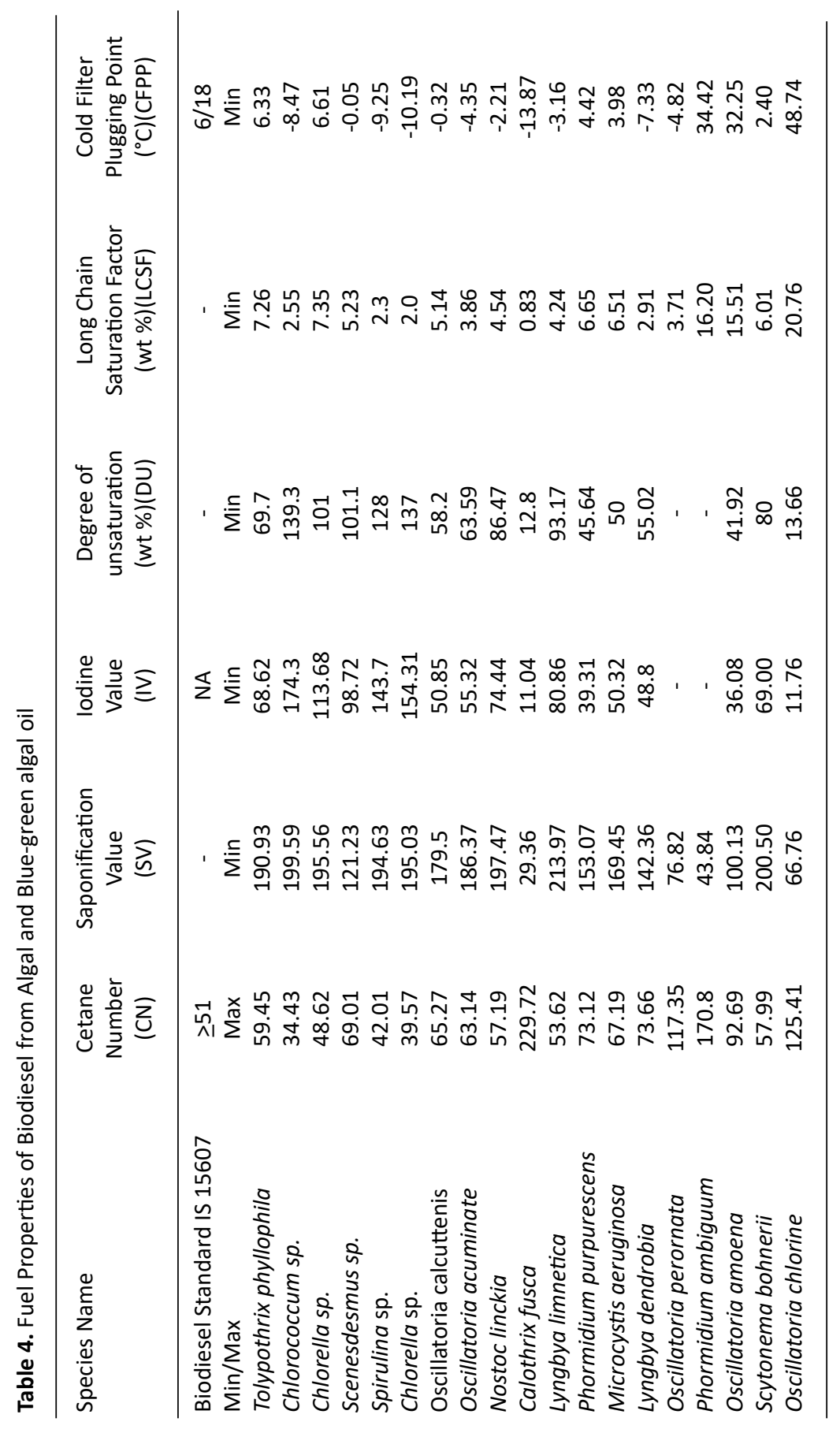


FAME of Tolypothrix phyllophila, principally containing, C $16: 0$ (up to $31.6 \%$ ). It is also rich in oleic acids (C 18:1). In the present study, we also compare the FAME of Tolypothrix phyllophila and 18 algal and blue-green algal strains found in India, with different literature. FAME analysis shows that highest palmitic acid (C 16:0) was found in Scytonema bohnerii and highest total saturated fatty acid was also found in Scytonema bohnerii, highest Oleic acid (C 18:1) and total monounsaturated fatty acid were found in Lyngbya limnetica, highest linoleic acid (C 18:2) was found in Scytonema bohnerii, and highest linolenic acid (C 18:3) was found in Chlorella sp., and total polyunsaturated fatty acids were found in Chlorococcum sp. and total highest total unsaturated fatty acids were also found in Chlorococcum sp. Microalgae rich in MUFAs (particularly, oleic acid (C 18:1) and palmitoleic acid (C 16:1) and SFAs are suitable for biodiesel production $^{55}$.

Various types of lipids, such as glycolipids, phospholipids, monoglyceride, diglyceride, and triglycerides, among others are produced by algae

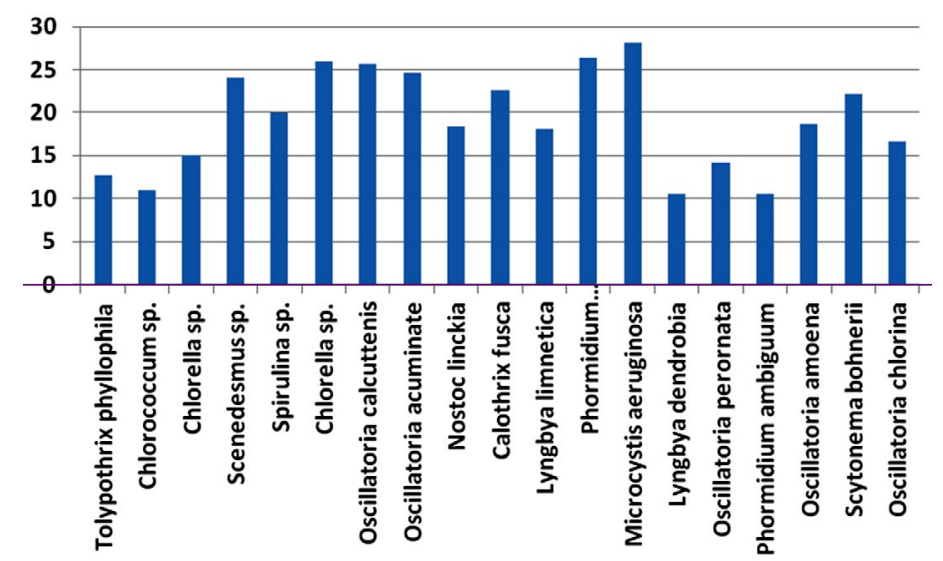

Fig.1. Oil percentage in different Algal and Blue-green algal Strains

Table 5. Corresponding Ourranking flow

\begin{tabular}{lll}
\hline Rank & Species & Phi \\
\hline 1. & Chlorella sp. & 0.3509 \\
2. & Phormidium ambiguum & 0.2982 \\
3. & Scytonema bohnerii & 0.1930 \\
4. & Tolypothrix phyllophila & 0.1754 \\
5. & Scenesdesmus sp. & 0.1404 \\
6. & Lyngbya limnetica & 0.1053 \\
7. & Nostoc linckia & 0.0702 \\
8. & Oscillatoria chlorine & 0.0702 \\
9. & Chlorococcum sp. & 0.0351 \\
10. & Oscillatoria amoena & 0.0351 \\
11. & Microcystis aeruginosa & -0.0526 \\
12. & Phormidium purpurescens & -0.0526 \\
13. & Spirulina sp. & -0.1053 \\
14. & Chlorella sp. & -0.1053 \\
15. & Oscillatoria calcuttenis & -0.1053 \\
16. & Oscillatoria acuminate & -0.1404 \\
17. & Oscillatoria perornata & -0.1579 \\
18. & Lyngbya dendrobia & -0.3158 \\
19. & Calothrix fusca & -0.6316
\end{tabular}

and blue-green algae and their percentage depend on each strains and the growing atmospheric conditions applied ${ }^{56}$.

The present study also showed that the estimated $\mathrm{CN}$ for algal and blue-green algal biodiesel varied between 34.43 to 229.72 . The Indian Standards shows that the CN value is equal to or more than 51 . In the present study except for Chlorococcum sp. (34.43), Chlorella sp. (48.6, 39.57), Spirulina sp. (42.01) all other strains have more than 51.

The Saponification Value estimated for biodiesels from this research varied between 29.36 to 213.97. Tolypothrix phyllophila, Chlorococcum sp., Chlorella sp., Spirulina sp., Oscillatoria acuminate, Nostoc linckia, and Scytonema bohnerii $\mathrm{SV}$ is in the similar range observed for vegetable oils (188-194 for sunflower oil, 196-202 for palm oil, and 189-195 for soybean oil $)^{42}$. This parameter, on the other hand, is highly changeable 
because it is also directly linked by the technology used for biodiesel production.

The lodine Value is a parameter represents the Degree of Unsaturation, concerning with the weighted sum of the masses of Mono Unsaturated Fatty Acid and Poly Unsaturated Fatty Acid. It is significant for biodiesel oxidative stability. High unsaturation levels may result in the polymerization of glycerides and the synthesis of deposits ${ }^{43}$. In comparison to biodiesel from vegetable oils ${ }^{42}$ most of the estimated lodine Value for the biodiesels from the algal and blue-green algal species (Table 4) were below than sunflower oil (110-143) and soybean oil (120-141) except Chlorococcum sp. (174.3), Chlorella sp. (154.31) and Spirulina sp. (143.7). For some algal and bluegreen algal species such as Calothrix fusca (11.04), Phormidium purpurescens (39.31), Oscillatoria amoena (36.08) and Oscillatoria chlorine (11.76), the lodine Value (Table 4) were below than, or similar to palm oil (48-56), indicative of lesser susceptibility to oxidative attack.
Saturated fatty acids have higher melting points in compare to unsaturated fatty acids. When most saturated fatty acid esters molecules are present in biodiesel, crystallization may take place at temperatures within the usual engine operation range ${ }^{43}$. Biodiesel rich in stearic acid methyl ester and palmitic acid methyl esters tend to present a poor Cold Filter Plugging Point (similar to a higher temperature of plugging point) because when liquid biodiesel is cooled, these fatty acid methyl esters are the first to precipitate [56]. In the current research work, the percentage of Stearic acid (C 18:0) (Table 2) were generally very low (below 3.98 $\%)$, except for Oscillatoria calcuttenis Phormidium purpurescens and Oscillatoria chlorina $(5.16,5.42$ and $4.76 \%$ respectively). These very low values of stearic acid (C 18:0) may have contributed to the lower temperatures of Cold Filter Plugging Point for the most of the studied species. The Cold Filter Plugging Point values calculated for biodiesel from the species focused in the current work between 13.87 (Calothrix fusca) to 48.74 (Oscillatoria chlorine).

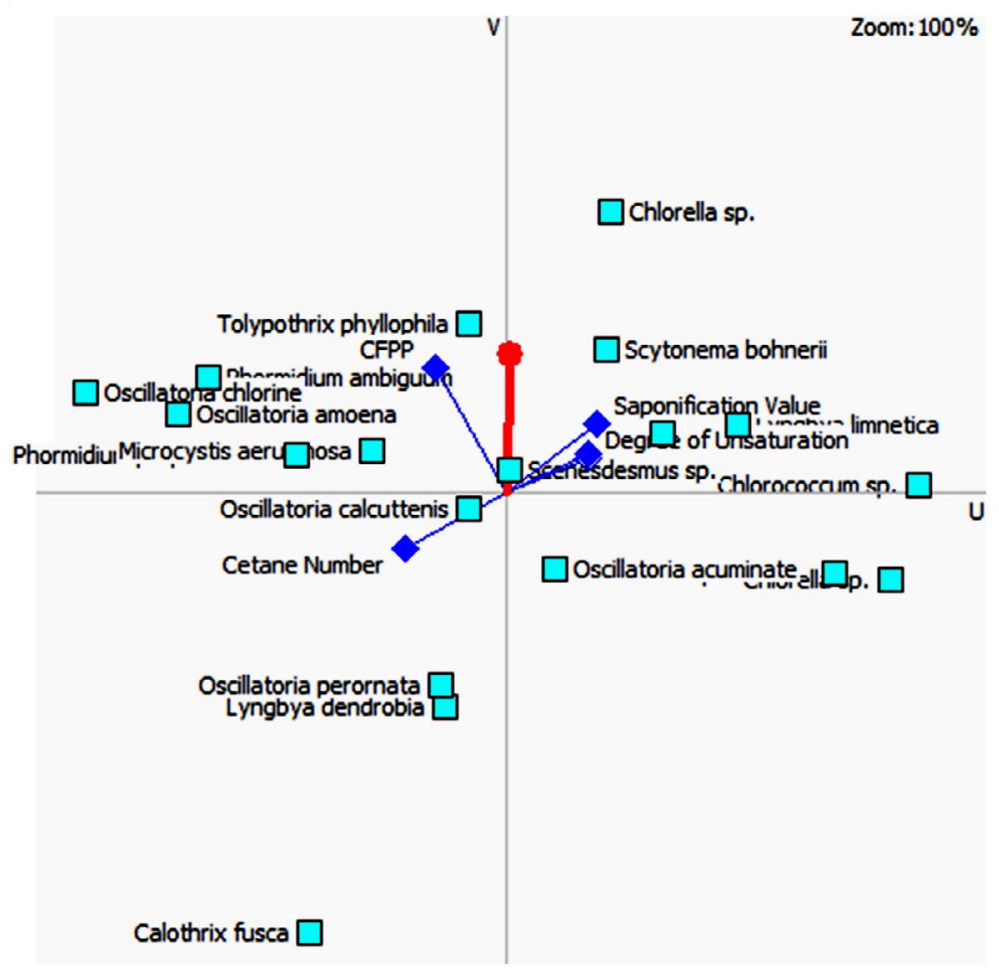

Fig. 2. GAIA plot of one algal species from the current study and eighteen algal and blue-green algal strains from different literature as shown in table no. 1, based on different biodiesel properties from table no. 4 and the decision vector 
An equal weighted to parameters, PROMETHEE analyses recognized that the Chlorella sp. and Phormidium ambiguum outranked while Calothrix fusca and Lyngbya dendrobia are the least suitable species in above mentioned nineteen species for biodiesel production.

\section{CONCLUSION AND FUTURE PROSPECTS}

The microalgae species isolated from other countries/continents may not perform better in India (Asia region) due to the remarkable variations in the regional climatic conditions. Therefore, domestic microalgal species must be isolated to serve the purpose. Indigenously isolated species may have adapted to the particular climatic conditions over their evolutionary period ${ }^{57}$.

In this study, 19 algal and blue-green algal strains were evaluated according to their lipid profiles and productivities. The total lipids percentage in dry biomass varied between $10.48 \%$ (Phormidium ambiguum) to $26.45 \%$ (Phormidium purpurescens).

As the physio-chemical properties of biodiesel are analysed by the molecular structures of the constituents fatty acid methyl esters, present research work proposes that the fattyacids composition of algae and blue-green algal oil must be main criteria for species selection, to make feasible the algal-based biodiesel industry.

According to their fatty acid profiles, various algae and blue-green algae exhibit immense potential to produce biodiesel within most of the biodiesel standards. Interestingly, most of the investigated species would hardly produce a lipid profile capable of fulfilling all the standard requirements for biodiesel production. But most of them harbour one or more main characteristics mandated for standard quality. Hence, it is worthwhile to generate designer biodiesel by calculated mixture of the distinct oil extracts, obtained from different species.

Realizing the importance of fatty acid methyl esters and the scarce information on the qualitative composition of algal oil, this research provides an important contribution for further bioprospection related to algae and blue-green algae for biodiesel production.

\section{ACKNOWLEDGMENTS}

We would like to thank the faculty members, and supporting staff of the Department of Oil Technology, HBTU for handling instruments. We would like to express our heartfelt thanks to Director, ICAR-IIPR for permitting me to work at ICAR-IIPR.

\section{CONFLICT OF INTEREST}

The authors declare that there is no conflict of interest.

\section{AUTHORS' CONTRIBUTION}

All authors designed the experiments. V. T. with the help of S.T. performed the experiments. V. T. with the help of A. D. analyzed the data. V. T. wrote the manuscript. All authors read and approved the manuscript. A. D. and R. K. Trivedi supervised and reviewed the manuscript.

\section{FUNDING}

None.

\section{DATA AVAILABILITY}

All datasets generated or analyzed during this study are included in the manuscript and/or the Supplementary Files.

\section{ETHICS STATEMENT}

Not applicable

\section{REFERENCES}

1. Chisti Y. Biodiesel from microalgae. Biotechnology Advances. 2007;25:294-306. doi: 10.1016/j. biotechadv.2007.02.001

2. Martins F, Felgueiras C, Smitkova M, Caetano N. Analysis of Fossil Fuel Energy Consumption and Environmental Impacts in European Countries; Energies; 2019;12: 964. doi: 10.3390/en12060964

3. https://www.epa.gov/ghgemissions/globalgreenhouse-gas-emissions-data accessed on 16/04/2020.

4. Asif M, Muneer T. Energy supply, its demand and security issues for developed and emerging economies. Renewable and Sustainable Energy Reviews.2007;11(7):1388-1413. doi: 10.1016/j. rser.2005.12.004

5. Owusu PA, Sarkodie SA. A review of renewable energy sources, sustainability issues and climate change mitigation. Cogent Engineering. 2016;3(1): 1167990. doi: 10.1080/23311916.2016.1167990

6. Demirbas A. The Importance of Bioethanol and Biodiesel from Biomass; Energy Sources, Part B: Economics. Planning and Policy. 2008;3(2): 177-185. doi: $10.1080 / 15567240600815117$

7. Demirbas A. Biofuels Sources, Biofuel Policy, Biofuel Economy and Global Biofuel Projections. Energy 
Conversion and Management. 2008; 49(8):2106-2116. doi: 10.1016/j.enconman.2008.02.020

8. Huang WD, Zhang YHP. Energy Efficiency Analysis: Biomass-to-Wheel Efficiency Related with Biofuels Production, Fuel Distribution, and Powertrain Systems. Plos One. 2011;6(7)e22113. doi: 10.1371/journal. pone. 0022113

9. Demirbas A. Political, Economic and environmental impacts of biofuels. A review; Applied Energy. 2009; 86: S108-S117. doi: 10.1016/j.apenergy.2009.04.036

10. Popp J, Lakner Z, Harangi-Rákos M, Fari M. The effect of bioenergy expansion. Food, energy, and environment; Renewable and Sustainable Energy Reviews. 2014; 32: 559-578. doi: 10.1016/j.rser.2014.01.056

11. Chen $H$, Wang $X$, Wang $Q$. Microalgal biofuels in China: The past, progress and prospects. GCB Bioenergy. Bioproducts for a Sustainable Bioeconomy. 2020;12:1044-1065. doi: 10.1111/gcbb.12741

12. Abdel-Raouf N, Al-Homaidanl AA, Ibraheem IBM. Microalgae and wastewater treatment. Saudi Journal of Biological Science. 2012; 19: 257-275. doi: 10.1016/j.sjbs.2012.04.005

13. Fu P, Secundo F. Algae and Their Bacterial Consortia for Soil Bioremediation. Chemical Engineering Transactions. 2016; 49: 427-432.

14. Kim EJ, Kim S, Choi HG, Han SJ. Co production of biodiesel and bioethanol using psychrophilic microalga Chlamydomonas sp. KNM0029C isolated from Arctic sea ice. Biotechnology for Biofuels. 2020; 13:20. doi: 10.1186/s13068-020-1660-z

15. Karmakar R, Rajor A, Kundu K, Kumar N. Production of biodiesel from unused algal biomass in Punjab, India. Petroleum Science. 2018; 15:164-175. doi: 10.1007/ s12182-017-0203-0

16. Knothe G. Dependence of biodiesel fuel properties on the structure of fatty acid alkyl esters. Fuel Process Technol. 2005; 86: 1059-1070. doi: 10.1016/j. fuproc.2004.11.002

17. Allen MM. Simple conditions for growth of unicellular blue-green algae on plates. J Phycol. 1968; 4(1): 1-4. doi: 10.1111/j.1529-8817.1968.tb04667.x

18. Prommuak C, Pavasant P, Quitain AT, Goto M, Shotipruk A. Microalgal Lipid Extraction and Evaluation of Single-Step Biodiesel Production. Engineering Journal. 2012;16(5):157-166. doi: 10.4186/ej.2012.16.5.157

19. Ramola B, Kumar V, Nanda M, et al. Evaluation, comparison of different solvent extraction, cell disruption methods and hydrothermal liquefaction of Oedogonium macroalgae for biofuel production. Biotechnology Reports. 2019; 24: e00340. doi: 10.1016/j.btre.2019.e00340

20. Busic A, Kundas S, Morzak G, et al. Recent Trends in Biodiesel and Biogas Production. Food Technology \& Biotechnology. 2018;56(2):152-173. doi: 10.17113/ ftb.56.02.18.5547

21. Dragone G, Fernandes B, Vicente AA, Teixeira JA. Third generation biofuels from microalgae; Current Research, Technology and Education Topics in Applied Microbiology and Microbial Biotechnology: 2010; 1355-1366.

22. Folayan AJ, Anawe PAL. Synthesis and characterization of Argania spinosa (Argan oil) biodiesel by sodium hydroxide catalyzed transesterification reaction as alternative for petro-diesel in direct injection, compression ignition engines. Heliyon. 2019; 5; e02427. doi: 10.1016/j.heliyon.2019.e02427

23. Ganesan R, Manigandan S, Samuel MS, et al. A review on prospective production of biofuel from microalgae. Biotechnology Reports.2020; 27. doi: 1016/j.btre.2020. e00509

24. Litinas A, Geivanidis S, Faliakis A, et al. Biodiesel production from high FFA feedstocks with a novel chemical multifunctional process intensifier. Biofuel Research Journal. 2020; 26: 1170-1177. doi: 10.18331/ BRJ2020.7.2.5

25. Prestegard SK, Erga SR, Steinrücken P, Mjos SA, Knutsen G, Rohloff J. Specific metabolites in a Phaeodactylum tricornutum strain isolated from western Norwegian fjord water. Mar. Drugs. 2016; 14(1):9. doi: 10.3390/ md14010009

26. Jena J, Nayak M, Panda HS, et al. Microalgae of Odisha Coast as a Potential Source for Biodiesel Production. World Environment.2012; 2(1): 11-16. doi: 10.5923/j. env.20120201.03

27. Anitha S, Narayanan JS. Isolation and Identification of Microalgal Strains and Evaluation of Their Fatty Acid Profiles for Biodiesel Production. International Journal of Pharmaceutical \& Biological Archives. 2012; 3(4): 939-944.

28. Sharathchandra $\mathrm{K}$ and Rajashekhar M. Total lipid and fatty acid composition in some freshwater cyanobacteria. J. Algal Biomass UtIn. 2011; 2(2): 8397.

29. Islam MA, Magnusson M, Brown RJ, Ayoko GA, Nabi MN, Heimann K. Microalgal Species Selection for Biodiesel Production Based on Fuel Properties Derived from Fatty Acid Profiles. Energies. 2013; 6: 5676-5702. doi: 10.3390/en6115676

30. Knothe G. Analyzing biodiesel: standards and other methods. J Am Oil Chem Soc. 2006; 83: 823-833. doi: 10.1007/s11746-006-5033-y

31. Meher LC, Vidya Sagar D, Naik SN. Technical aspects of biodiesel production by transesterification-a review. Renew Sust Energ Rev. 2006; 10: 248-268. doi: 10.1016/j.rser.2004.09.002

32. Mittelbach M. Diesel fuel derived from vegetable oils, VI: Specifications and quality control of biodiesel. Bioresource Technology. 1996; 56(1):7-11. doi: 10.1016/0960-8524(95)00172-7

33. Akubude VC, Nwaigwe KN, Dintwa E. Production of biodiesel from microalgae via nano catalyzed transesterification process: A review. Materials Science for Energy Technologies. 2019;2:216-225. doi: 10.1016/j.mset.2018.12.006

34. Deshmukh S, Bala K Kumar R. Selection of microalgae species based on their lipid content, fatty acid profile and apparent fuel properties for biodiesel production. Environmental Science and Pollution Research. 2019; 26: 24462-24473. doi: 10.1007/s11356-019-05692-z

35. Knothe G. Some aspects of biodiesel oxidative stability. Fuel Process Technol. 2007; 88: 669-677. doi: 10.1016/j.fuproc.2007.01.005 
36. Sinha SK, Gupta A, Bharalee R. Production of biodiesel from freshwater microalgae and evaluation of fuel properties based on fatty acid methyl ester profile. Biofuels. 2016;7(1):69-78. doi: 10.1080/17597269.2015.1118781

37. Demirbas A. Biodiesel production from vegetable oils via catalytic and noncatalytic supercritical methanol transesterification methods. Prog Energy Combust Sci. 2005;31:466-487. doi: 10.1016/j.pecs.2005.09.001

38. Knothe G, Matheaus AC, Ryan TW III. Cetane numbers of branched and straight chain fatty esters determined in an ignition quality tester. Fuel. 2003;82:971-975. doi: 10.1016/S0016-2361(02)00382-4

39. Giakoumis EG, Sarakatsanis CK. A Comparative Assessment of Biodiesel Cetane Number Predictive Correlations Based on Fatty Acid Composition. Energies. 2019;12: 422. doi: 10.3390/en12030422

40. Vijayaraghavan $\mathrm{K}$ and Hemanathan K. Biodiesel Production from Freshwater Algae. Energy Fuels. 2009; 23: 5448-5453. doi.: 10.1021/ef9006033

41. https://www.bdai.org.in/pdf/pdf1.pdf accessed on $16 / 04 / 2020$

42. Krisnangkura KA. Simple Method for estimation of cetane index of vegetable oil methyl esters. J Am Oil Chem Soc. 1986;63:552-553. doi: 10.1007/ BF02645752

43. Francisco EC, Neves DB, Jacob-Lopes E, Franco TT. Microalgae as feedstock for biodiesel production: carbon dioxide sequestration, lipid production and biofuel quality. J Chem Technol Biotechnol. 2010; 85:395-403. doi: 10.1002/jctb.2338

44. Jo SW, Do JM, Na H, Hong JW, Kim IS, Yoon HS. Assessment of biomass potentials of microalgal communities in open pond raceways using mass cultivation. PeerJ. 2020;8:e9418. doi: 10.7717/ peerj.9418

45. Dunn RO. Effect of antioxidants on the oxidative stability of methyl soyate (biodiesel). Fuel Process Technol. 2005;86:1071-1085. doi: 10.1016/j. fuproc.2004.11.003

46. Ramos MJ, Fernandez CM, Csas A, Rodriguez L, Perez A. Influence of fatty acid composition of raw materials on biodiesel properties. Bioresour Technol. 2009; 100: 261-268. doi: 10.1016/j.biortech.2008.06.039

47. Knothe G. Improving biodiesel fuel properties by modifying fatty ester composition. Energy Environ. Sci. 2009; 2: 759-766. doi: 10.1039/b903941d

48. Knothe G. "Designer" biodiesel: optimizing fatty ester composition to improve fuel properties. Energy Fuels. 2008;22:1358-1364. doi: 10.1021/ef700639e

49. Stansell GR, Gray VM, Sym SD. Microalgal fatty acid composition: implications for biodiesel quality. Journal of Applied Phycology, 2012; 24: 791-801. doi: 10.1007/ s10811-011-9696-x

50. Kramadibrata MAM, Nurjanah S, Muhaemin $M$, et al. Selecting Biofuel Obtained from Sunan Pecan Oil for Diesel Engine Fuel. J of Agricul Sci \& Technol A. 2019;9:323-328. doi: 10.17265/2161$6256 / 2019.05 .005$

51. Espinasse B, Picolet G, Chouraqui E. Negotiation support systems: A multi-criteria and multi-agent approach. Eur. J. Oper. Res. 1997; 103: 389-409. doi: 10.1016/S0377-2217(97)00127-6

52. Brans JP, Mareschal B. PROMETHEE Methods. In Multiple Criteria Decision Analysis: State of the Art Surveys; Springer: New York, NY, USA: 2005; 163-186. doi: 10.1007/0-387-23081-5_5

53. Griffiths MJ, Harrison STL. Lipid productivity as a key characteristic for choosing algal species for biodiesel production.J Appl Phycol. 2009;21:493-507. doi: 10.1007/s10811-008-9392-7

54. Huerlimann R, de Nys R, Heimann K. Growth, lipid content, productivity and fatty-acid composition of tropical microalgae for scale-up production. Biotechnol Bioeng. 2010; 107(2):245-257. doi: 10.1002/bit.22809

55. Stansell GR, Gray VM, Sym SD. Erratum to: Microalgal fatty acid composition: implications for biodiesel quality. J Appl Phycol. 2012; 24:985. doi: 10.1007/ s10811-012-9824-2

56. Nascimento IA, Marques SSI, Cabanelas ITD, et al. Screening Microalgae Strains for Biodiesel Production: Lipid Productivity and Estimation of Fuel Quality Based on Fatty Acids Profiles as Selective Criteria. Bioenerg. Res. 2013; 6:1-13. doi: 10.1007/s12155-012-9222-2

57. Gill SS, Mehmood MA, Ahmad N, et al. Strain selection, growth productivity and biomass characterization of novel microalgae isolated from fresh and wastewaters of upper Punjab, Pakistan. Frontiers in Life Science. 2016; 9(3): 190-200. doi: $10.1080 / 21553769.2016 .1204957$ 